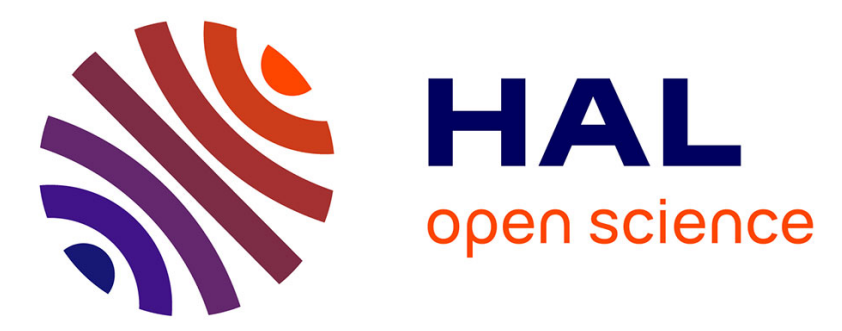

\title{
Will the Visualization of Internet Affect Languages of Education?
}

\author{
Jaana Holvikivi
}

\section{To cite this version:}

Jaana Holvikivi. Will the Visualization of Internet Affect Languages of Education?. 1st International Conference on Sustainable ICT, Education, and Learning (SUZA), Apr 2019, Zanzibar, Tanzania. pp.185-194, 10.1007/978-3-030-28764-1_21. hal-02515733

\section{HAL Id: hal-02515733 \\ https://hal.inria.fr/hal-02515733}

Submitted on 23 Mar 2020

HAL is a multi-disciplinary open access archive for the deposit and dissemination of scientific research documents, whether they are published or not. The documents may come from teaching and research institutions in France or abroad, or from public or private research centers.
L'archive ouverte pluridisciplinaire HAL, est destinée au dépôt et à la diffusion de documents scientifiques de niveau recherche, publiés ou non, émanant des établissements d'enseignement et de recherche français ou étrangers, des laboratoires publics ou privés. 


\title{
Will the Visualization of Internet Affect Languages of Education?
}

\author{
Jaana Holvikivi \\ Espoo, Finland \\ jaana.holvikivi@gmail.com
}

\begin{abstract}
The impact of digitalization on daily activities has become pervasive, even in the Global South. The dominance of colonial languages in education is both strengthened and weakened by latest technologies. The paper asks whether new technologies could bring native language education available to a larger number of children in the world. The great affordances of new technological innovations could be utilized by school systems, and give students tools to enhance their learning. Mobile and visual technologies such as videos and emoji can empower people and give opportunities for wider communication if policies are enacted to support underprivileged people and grassroots activity. However, intensification of research is needed to outline promising futures for education of minorities, disabled and indigenous peoples.
\end{abstract}

Keywords: education, indigenous languages, future, emoji, digitalization

\section{Introduction}

Digitalization and ICT have a tremendous effect on daily activities all over the world. Even though computer use was until recently a privilege of citizens of industrialized nations, the access to mobile technologies has reached large populations also in the Global South [1]. Digitalization has the potential of being empowering for people with modest means as the low cost of mobile devices has brought them to the reach of more people than ever. Positive effect can be observed in areas where people previously had no access to global communication, but with mobile devices they can use banking services, conduct business, and access health care information among other activities. On the other hand, the reliance on English as the language of computer has been challenged by the increased use of video and images, as well as the opportunity to use other signs than alphabetic characters. The changes in technology penetration have recently been faster than ever, and there is no reason to suppose that the pace of technical development would slow down in the near future [1]. The rapid change poses a challenge to research and policy making.

This paper aims to take some fresh perspectives to the use of ICT in education, challenges of education in multilingual countries, and what would be needed for creating equal opportunities to the underprivileged and minority populations in the digitalized world. A crucial question is whether the people in developing countries 
will be able to appropriate novel technologies in their own ways to support their own communication needs. Moreover, the paper will discuss briefly some aspects of the current state of technological development and its global distribution, particularly the shift towards East Asia. The cognitive basis on ICTs is in the Western school system and Western science, which dominate the research and education. Furthermore, the paper will present some trends that might impact the dominance of English in computer systems, and consider chances that it will fade soon. What will be the future of world's thousands of small languages? Will modern technology destroy them or help them to survive? Moreover, the cognitive requirements by technical systems and mobile applications will be considered, and the use of social media in new contexts is reflected upon.

\section{Languages in Education and Cognitive Development}

There are about 6000 languages spoken in the world currently, but only 3\% of them are spoken in Europe [2]. In particular, the multiplicity of languages affects education systems in Africa and Asia. Despite the large number of native languages, school languages in the Global South usually are either colonial languages such as English, Spanish or French, or national languages such as Swahili or Hindi. Even though bilingualism obtained in school could greatly benefit the intellectual development of the child, the benefits are lost if the child is not able to acquire fluency in her school language, because higher order thinking and problem solving rely on language. For the development of abstract and scientific thought, mastery of the working language is required [3]. Even development of mathematical skills is heavily influenced by the language of instruction [4].

In many African countries such as Kenya school tuition is only given in a few languages, and moreover, parents want their children to learn English as it is believed to open more possibilities for future education and career. However, if the student does not master English or the other school language well, she cannot really learn any demanding concepts, as also Kioko et al demonstrate [5].

One of the countries that prefer colonial languages in education is Rwanda. The Rwandan government decided to switch the country's entire education system from French to English in its move away from Francophone influence in 2008 [6]. The first three years of primary education are conducted in local Kinyarwanda, and after that in English. Just 8 percent of Rwandans speak French, and 4 percent speak English, according to the government, but teachers have previously been educated in French. In 2009, out of Rwanda's 31000 primary school teachers, only 4700 were trained in English, and out of Rwanda's 12000 secondary school teachers, only 600 were trained in English. Pearson [7] in her article "Policy without a plan: English as a medium of instruction in Rwanda" stresses that there was no implementation plan, neither a follow-up. Recent statistics show that despite some major achievements in Rwanda's attempts to achieve universal primary education, it currently has one of the worst repetition rates in the Sub-Saharan region. School attendance is high but students do not pass grades. [8] 
On the other hand, mother tongue instruction has been a success in Ethiopia, where schooling formerly had been offered only in the majority language Amharic and English at later stages. Other 20 languages (there are 85 different languages in the country) were added to primary instruction since 1994 with good results, as more children completed primary school. Philippines has moved to multilingual model, as well. [9] Nevertheless, mother tongue instruction is a demanding process to implement for a country, as it requires development of the written language if it did not exist earlier, training of teachers and production of learning materials and textbooks. India has started many regional projects to support indigenous language teaching in schools, but taken the limited resources and enormous number of languages, only a small fraction of the population has been reached [10].

As comparisons of language policies between former colonies of European countries show, most policies are based on political power considerations, not educational science. This is the case in (former) French colonies, as well [11], and it also is displayed in the language policies of Russia and former Soviet countries such as Estonia, Latvia and Lithuania. The right to mother tongue instruction often is undermined by national politics. Furthermore, all countries with immigrant populations have to acknowledge their language education needs, which always is a significant investment for the education system.

Additionally, thinking models stemming from Western schooling are dominated by logical, hierarchical thinking, objectivity removed from body and emotions, and individual performance, not social collaboration. These culturally influenced factors can hinder student learning, as has been understood in Bolivia where the new primary school curriculum guarantees education in the native language, Aymara, and simultaneously supports native spirituality and communities [12].

Educational policies in European countries emphasize higher order thinking skills, computer science and computational thinking as a part of essential 21st century skills that students need in the digital world. But how can education in the Global South help the population in dealing with the new challenges? Schools in Africa, Asia and Latin America very seldom have the means to teach computing-related topics because the lack of equipment, electricity and telecommunications. Moreover, the teachers are even less skilled in digitalization than in Europe.

A revealing example comes from Kenya, which introduced an ambitious policy to teach computer skills in all secondary schools according to the Vision 2030 Economic Stimulus Programme by Kenyan government The government equipped 1050 secondary schools with computers: 11 PCs, 1 laptop, 1 video projector and one 1 printer for each school. The aim of the initiative was that teachers would be able to integrate ICT into the curriculum. However, there can be as many as 80 to 120 students in one class, which makes it impossible to let all students to work with computers, or teachers to acquire digital skills for themselves. [13]

Amina Charania from Tata Foundation, India, stated "We cannot talk about computational thinking before we have brought basics of digital literacy to the school teachers in rural India.” [14] Tata foundation is supporting projects that introduce digital skills to teachers who in turn start mentoring another group of teachers. The 
model seems to be suitable in a country with a huge rural population and great number of native languages.

\section{Design of New Technologies}

Computers were invented around 1940 in the United States, where also programming and later the internet were born. Computer technology is based on Western science and thinking, and even programming languages and computer operation rely on one language only, English. For a long time, the use of English and its alphabet in all telecommunications restricted users in other countries and strengthened the global dominance of English language. Moreover, the American dominance in entertainment industry and in internet applications seemed to ensure that English would be the only important language in the future.[1]

The technologies are still mainly developed by US and Western companies where the employees share the schooling background, science education and behavioural norms, as well as cognitive styles. Therefore, the logic of systems and applications is purely based on Western science. Moreover, the psychology behind the usability and user interfaces of the devices and applications is based on research made among US college students, which hardly represents the psychology of the global population. Most of the research that has been published in psychology journals has been conducted by Western researchers (96\%), using university students as test subjects (in $67 \%$ of the cases in American samples). Henrich et al [15] argued that the sample thus obtained is severely biased, and in some cases could be considered as an outlier of the global population. Comparative studies indicate very different behavioural patterns in other populations, particularly in Asian countries and small societies.

Moreover, as companies aim at generating profits, they mainly design for the population that can best afford their products. People with less means have to adapt to whatever is offered on the market. People in Asia, Africa and Latin America have predominantly been consumers; not part of the development process, even though the most active internet users are in South-East Asian and Latin American countries, Philippines leading the statistics with over alleged 10 hours a day [16]. The Japanese industry was the first to start alternative product development, and has introduced a variety of technologies, games, robotic applications, etc. which have succeeded globally. The changes in the global user population will have an effect on the products in the future, as the Chinese economy is growing fast, and other emerging economies follow. The R\&D of ICT products increasingly will take place in the East. [17]

\subsection{New ways of communication emerge}

The English alphabet uses only 27 characters. For decades, computer systems were predominantly built to use that character set in texts following standards such as ASCII and ANSI. As most Western European languages had more alphabetic characters, they were added to code sets as alternatives. Later, Cyrillic, Greek and Arabic characters were added, and finally, the Unicode recommendation that was 
drafted in 1988 recognizes all world's languages and their writing systems [18]. Despite the creation of the industry standard, it has taken a long time to include all characters into existing computer systems. Because of the complex writing system of the Japanese language, ideogram and syllabic alternatives were developed early in Japan. Currently, major Asian languages can easily be written using mobile or computer keyboards, including Chinese, Hindi, and Arabic.

On the other hand, language learning and processing is becoming less dependent on writing, when videos and recorded speech can be distributed through mobile networks, and speech analysis allows pronunciation practice. Foreign or second language learning has become much easier than before when numerous language tutoring videos are distributed over the internet. The old pedagogy of grammar and vocabulary drills can be replaced by more natural ways of adopting new languages. Additionally, new translation tools take some of the learning burden away.

\subsection{Emoji}

A new communication style has started with the use of cute little symbols called emoji, which are not connected to any language. It is not surprising that the origin of emoji is also in Japan where the telecommunications companies started to add them to keyboards of mobile phones in 1999. Even though emoji can be conceived as an extension of the text-based emoticons such as the smiley, they are also connected to the Japanese communication culture that has favoured cute images and symbols already for decades [19]. Routinely, the authorities in Japan soften orders and prohibitions by sweet pictorial expression such as childish traffic signs. Emoji also fit rather seamlessly to the Japanese writing that habitually includes four different types of characters (hiragana, katakana, kanji and Latin alphabet). The word emoji is Japanese and means picture-character. [18-22]

The emoji are currently included in the Unicode being therefore global [18]. Each emoji has a defined name in the code but people do not necessarily know the names when they choose to include some emoji in their messages. Therefore, the emoji have varied meanings depending on the user community, platform, or individual user. No correct code for usage can be devised. In fact, there are heated discussions on this such as the meaning of the most popular emoji, the loudly crying face [23]. There are also culturally sensitive emoji such as thumbs up which can be offensive in some countries. The emoji are hugely popular in China where local varieties exist on platforms such as WeChat. Moreover, the pictorial expression can be used for hidden messages and to recode the words of the message because Chinese characters often convey one idea or word, as well. [24]

Research on emoji use is accumulating fast [25, 26]. Many studies have analysed emoji use by text context or country differences in Twitter where the API allows downloading of large data sets [27]. The research has found differences between geographical areas and among countries. However, Twitter is a platform for political and business communication which is not the most typical area for casual conversation. Actually, Instagram is a more typical platform for emoji, and already in 2016 nearly half of Instagram messages contained emoji [18]. Emoji users tend to be 
young people who use them in informal settings. As the name "emoticon" originally referred to, emoji are also carriers of feeling rather than factual information. They soften the message, making it less threatening.

Certain emoji are popular all over the world with laughing or crying faces on top of the list. However, differences between countries have been detected: in France, heartsymbols are among the most popular emoji in text messages according to Lu et al [25]. The French also used emoji more frequently than other nationalities in the study. However, the test population in this study comprised of predominantly young adults.

Despite the active research interest, it will be hard to predict the future importance of emoji as means of communication. The Unicode consortium is dominated by US based technology giants and their representatives, therefore they are hardly representative of the world population and the variety of cultural expressions. Will the emoji be a new global "language" or replaced by something else soon? Their similarity to logograms in some aspects might be important in the future. In any case, they are a good example of challenges to the dominance of English in global communication, and the extremely fast spread of new fashions in the internet.

\section{$4 \quad$ Reading Logograms and Other Characters}

The Western Latin alphabet is one of the simplest writing systems. It is closely related to other Greek-derived alphabets such as Cyrillic writing used in Russia. The Arabic consonant system is historically related to alphabets, but, significantly, it is written from right to left. Chinese characters are complex, and the system contains thousands of logograms that can be pronounced in several ways. The perception of an individual character is visually more demanding than that of alphabetic letters, as one character may consist of up to 23 strokes. Writing Chinese characters requires good hand movement control and visual memory, therefore Chinese speakers employ visuomotor brain areas for reading and writing to a larger extent than alphabet users [28]. Chinese is written in varied directions, including from left to right and top to bottom. Additionally, other important writing systems include various syllabic writings in South and East Asia such as Hindi, Bengali, and Thai.

Reading as a cognitive process is somewhat different when the characters are not alphabetic but logograms. Pictorial expressions are processed by different parts of the brain than alphabetic text. Most research concerning language and number processing has examined Indo-European language speakers (such as English, German, and Italian) who read alphabetic characters and use Arabic numerals [29]. A growing body of evidence points to differences in reading, processing numbers, and doing mental arithmetic in people who use predominantly logographic characters. Most probably these differences extend to computer-based mental functioning, as well.

Intensive research concerning the processing of Chinese and Japanese languages has revealed significant differences in brain networks that are involved in reading logographic or alphabetic texts. Bolger et al [29] found in their meta-analysis of alphabetic systems, Chinese, and Japanese writings, that the brain regions involved in word reading in these language systems are mainly the visual word form area in the 
left mid-fusiform gyrus. Nevertheless, certain localization differences are obvious between logographic and alphabetic systems. A study that compared eye movements in different visual and character-related tasks also showed specific patterns for Chinese characters. Chinese participants' fixations were more numerous and of shorter duration than those of their American counterparts while viewing faces and scenes, and counting Chinese characters in text [30].

A study on information technology students reactions to special characters that are used in computer systems showed that results varied depending on students native language and school languages. The study compared character perception differences in Ethiopian (syllabic writing), Chinese (logographic writing), and European information technology students. Working memory performance was tested for numbers, letters, and special characters such as \#, / and \&. Preliminary results indicated that a person's native character system affects the ability to mentally manipulate and memorize different types of characters. [31]

Evidently, the visualization of internet and mobile communication could also be studied from the perception aspects, as well as from the emotional point of view, which opens up numerous interesting questions for future study.

\section{$5 \quad$ Social Media and Other Future Considerations}

Technology has multiple various kinds of effects on education and language. As best, it is found to be useful in indigenous language support and revitalization [32], which gives some hope to the future of world's minority languages and linguistic diversity. Technology enables communication and education for dispersed languages with small numbers of speakers through distance education. Videos, podcasts and streaming of tuition could all make it less costly to develop educational materials. Students use videos for learning already heavily in industrialized countries, which shows that they are a popular and useful way to develop new skills if available. In countries such as Indonesia, Brazil and Thailand where people are purportedly spending around 10 hours a day in using social media [16], the potential for educational videos should be enormous.

However, there also are less innocent developments caused by technology and social media, in particular. The consequences of digitalization and social media are unpredictable and can be disastrous in some cases such as the infamous case of Facebook and the Rohingya. Coverage of smart phones in Myanmar exploded in 2014-17 but the population had no education in understanding social media and was an easy prey to malignant rumours in the Facebook [33]. However, that kind of problem is not confined to newly developed mobile infrastructure but a similar dilemma has emerged in rich countries where other countries' spy organizations have been able to influence election results (in the US and U.K.) through false information in social media. Moreover, even governments are publishing manipulated videos for political aims.

Whatsapp rumours and India lynchings [34] are another troubling case, which has claimed tens of victims. Rumours accusing people of kidnapping children have been 
circulated widely in Whatsapp groups, and angry crowds have attacked innocent passers-by. Actually, the phenomenon had started already before internet access with simple text messages. In Nigeria, text messages were circulated that were rumoured to cause voodoo deaths. More recently, in the neighbouring country Niger, marriage customs are affected by public displays in social media [35].

\section{Conclusions}

Position of English as the growing universal language was supported by the early years of internet where text-based communication was dominant and the English ASCII alphabet was the only choice. Text messages forced people to use English character sets and sometimes even the language. However, the trend has turned as the bandwidth on communication has expanded, pictorial and video expression is feasible, and use of any local characters in writing is possible with digital devices. Automatic translation based on speech reduces the need for knowing other languages well. Additionally, certain strong cultural influences compete stronger than ever with American cultural dominance in global entertainment such as K-pop, anime and manga, and Bollywood.

The educational system including policy makers, schools and teachers now has a great opportunity to seize the affordances of the new and emerging technologies. Education can utilize videos, cameras, speech recognition, broadband mobile communications, as well as emoji-type pictorial expressions. The creative capacity of the young generation, school children, could be harnessed to this aim. Children want to learn, and they are quick to find new ways to improve their skills. Pedagogy that is based on knowledge construction and inquiry based learning is a great tool in using new technologies to produce materials and learning.

Cognitive differences in computer operation have implications for professional activities in non-Western countries, which would need further study. Whether cognitive differences will be mitigated by the development of technology or worsen because of its more frequent use, is not yet clear. However, the more technology-led future will require stronger thinking skills than ever [36]. Thinking skills are developed in the education from early on, therefore, the importance of quality education and further training for teachers is crucial. Mother tongue education in primary schools is one of the keys to successful cognitive development. Development policies and projects need to emphasize quality education following the principle that education has to be first, and technology is in its service.

\section{References}

1. ITU. Measuring the Information Society Report 2018. at http://itu.int

2. Crystal, D.: The Cambridge Encyclopedia of language. $3^{\text {rd }}$ edition. Cambridge U Press. Cambridge (2010)

3. Bialystok, E., Craik, F., Luk, G.: Bilingualism: consequences for mind and brain, Trends in cognitive sciences, Vol. 16, 4, p. 240-250 (2012) 
4. Haag, N., Heppt, B., Stanat, P., Kuhl, P., Pant, H. A.: Second language learners' performance in mathematics: Disentangling the effects of academic language features, Learning and Instruction, Vol. 28, pp. 24-34 (2013)

5. Kioko, A.N., Ndung'u, R.W., Njoroge, M.C. : Mother tongue and education in Africa: Publicising the reality. Multiling.Ed. 4: 18 (2014)

6. McGreal, C.; Rwanda to switch from French to English in schools, 14.10.2008. At: http://www.guardian.co.uk/world/2008/oct/14/rwanda-france. (2008)

7. Pearson, P.: Policy without a plan: English as a medium of instruction in Rwanda, Current Issues in Language Planning, 15:1,39-56 (2014)

8. Watkins, K.: Too Little Access, Not Enough Learning: Africa's Twin Deficit in Education, 16.1.2013. At: http://www.brookings.edu/research/opinions/2013/01/16-africa-learningwatkins. (2013)

9. SIL International. At http://www.sil.org

10. Singh, N. K. (2013). Globalization and Multilingualism: Case Studies of Indigenous Culture-based Education from the Indian Sub-continent and Their Implications. International Journal of Multicultural Education, 15(1).

11. Spolsky, B.: Language policy in French colonies and after independence. Current Issues in Language Planning . Vol. 19:3, pp. 231-315 (2018)

12. Filpus, L.: Bolivia: new primary school curriculum guarantees education in the native language, Aymara. Opettaja 13 (2017)

13. Ang'ondi, E. K.: Teachers Attitudes and perceptions on the use of ICT in teaching and learning as observed by ICT champions, in WCCE 2013 vol 1: Torun, Poland ( 2013).

14. Charania, A.: OCCE2018 keynote 28.6.18 at http://occe.2018.ocg.at/ (2018)

15. Henrich, J., Heine, S. J., Norenzayan, A.: The weirdest people in the world?. Behavioral and Brain Sciences, Vol. 33, 2-3, pp. 61-83 (2010).

16. Lamb, K.: "Philippines tops world internet usage index with an average 10 hours a day" at https://www.theguardian.com/technology/2019/feb/01/world-internet-usage-indexphilippines-10-hours-a-day (2019)

17. Romei, V., Reed, J.: The Asian century is set to begin. Financial Times. At https://www.ft.com/content/520cb6f6-2958-11e9-a5ab-ff8ef2b976c7 (2019)

18. Unicode Organization at http://www.unicode.org

19. Gn, J.: Emoji as a "language” of cuteness. First Monday. Vol 23:9 (2018) (online)

20. Davis, M., \& Edberg, P.: Unicode Emoji. Version 10.0 (21.5.2018) Retrieved from http://unicode.org/reports/tr51/

21. Lufkin, B.: Why are there so many Japanese emoji? At http://www.bbc.com/capital/story/20180716-why-there-are-so-many-japanese-emoji (2018)

22. Evans, V.: The Emoji Code: How Smiley Faces, Love Hearts and Thumbs Up are Changing the Way We Communicate. Michael O'Mara, UK. (2017).

23. Kelly, J. Loudly crying face. At https://blog.emojipedia.org/emojiology-loudly-cryingface/ (13.6.2018)

24. Yan, D.: When chatting with Chinese, know your emojis. at: http://www.chinadaily.com.cn/china/2016-02/02/content_23356908.htm (2016)

25. Lu,X., Ai,W., Liu, X. , Li, Q., Wang, N., Huang, L., Mei, Q.: Learning from the Ubiquitous Language: an Empirical Analysis of Emoji Usage of Smartphone Users. UBICOMP '16, Germany (2016)

26. Emojitracker at http://Emojitracker.com

27. Coats, S.: Skin Tone Emoji and Sentiment on Twitter. At https://arxiv.org/ftp/arxiv/papers/1805/1805.00444.pdf (2018) 
28. Chen, C., Xue, G., Mei, L., Chen, C.; Dong, Q.: ”Cultural neurolinguistics,” Prog Brain Res., 178- 159 (2009).

29. Bolger, D. J., Perfetti, C. A., Schneider, W.: Cross-cultural effect on the brain revisited: Universal structures plus writing system variation, Human Brain Mapping, Vol. 25, 92104 ( 2005).

30. Rayner, K., Li, X., Williams, C. C., Cave, K. R., Well, A. D.: ”Eye Movements during Information Processing Tasks: Individual Differences and Cultural Effects,” Vision Res, Vol 47; 21, 2714-2726 (2007)

31. Holvikivi, J.: Cultural variation in perception and coding in IT students, 10th IFIP World Conference on Computers in Education, Torun, Poland; Vol 1, 200-208.(2013)

32. Galla, C.K.: Indigenous language revitalization, promotion, and education: function of digital technology, Computer Assisted Language Learning, 29:7, pp. 1137-1151 (2016)

33. Myanmar Rohingya: Why Facebook banned an army chief. At https://www.bbc.co.uk/news/world-asia-45326928 (2018)

34. Rahman, S.: Fake news often goes viral: WhatsApp ads warn India after mob lynchings at https://www.theguardian.com/world/2018/jul/13/fake-news-whatsapp-ads-india-moblynchings (2018)

35. Maclean, R.: New clothes and cash: social media fuels Niger 'bride price' controversy at https://www.theguardian.com/global-development/2018/jul/23/how-social-media-isrevolutionising-marriage-in-niger (2018)

36. Holvikivi, J.: Culture and cognition in information technology education. Espoo: SimLab publications, Finland (2009) 